Seção Temática: Os Recursos Públicos em Disputa

Volume 11 - 2021 | n. 36

\title{
A Parceria Global pela Educação e o Financiamento da Educação: países, atores e contribuições
}

\author{
Rui da Silva \\ Universidade do Porto, Centro de Estudos Africanos da Universidade do Porto, Porto - Portugal \\ Joana Oliveira \\ Instituto Politécnico de Viana do Castelo, Escola Superior de Educação (ESE-IPVC), Viana do \\ Castelo - Portugal
}

\section{Resumo}

Neste texto analisa-se o fluxo de doações para a Parceria Global para a Educação no período de 2011 a 2020, caso elucidativo da problemática do financiamento da educação nos países do Sul Global, principalmente os países da África Subsaariana. Para tal, constituiu-se um corpus documental cuja análise obedeceu a uma estratégia indutiva que visou responder às questões: quem são os doadores, que financiamento disponibilizam e em que ano(s)? Numa primeira fase, procedeu-se à identificação exaustiva dos atores que fornecem apoio financeiro e a sua categorização. Numa segunda fase, conduziu-se uma estatística descritiva. A análise realizada permite inferir que há três países que se destacam em termos absolutos como os principais doadores desse Fundo - Reino Unido, Noruega e Dinamarca. A análise permitiu, ainda, constatar que aparecem como doadores Fundações, embora a sua contribuição seja esporádica, em menor volume e inconsistente ao longo dos anos. O setor privado não faz contribuições financeiras, apenas em espécie.

Palavras-chave: Financiamento da Educação. Sul Global. Parceria Global para a Educação.

\section{The Global Partnership for Education and Education Financing: countries, actors, and contributions}

\begin{abstract}
This paper analyzes the flow of donations to the Global Partnership for Education in the period from 2011 to 2020 , an illustrative case of the problem education funding in the countries of the Global South, especially the countries of Sub-Saharan Africa. A documental corpus was used to answer the questions: who are the donors, what funding do they provide and in what year(s)? As a first step, we identified the actors providing financial support and categorised them. In a second phase, we conducted a descriptive statistic. The analysis shows that there are three countries that stand out as the main donors - United Kingdom, Norway, and Denmark. The analysis also allowed us to conclude that Foundations appear as donors, although their contribution is sporadic, smaller in volume and inconsistent over the years. Private companies have not contributed directly to the fund with money but gave in-kind support.
\end{abstract}

Keywords: Education Funding. Global South. Global Partnership for Education. 
A Parceria Global pela Educação e o Financiamento da Educação

\section{Introdução}

Partimos do pressuposto de que nos encontramos num contexto de política educacional no qual os países do Sul Global têm uma grande intensidade de influências mundiais e está a ocorrer o surgimento de um conjunto de novos atores na arena global - atores privados transnacionais, organizações de investigação e empreendedores - que promovem políticas educacionais com as quais se identificam (BALL, 2012; VERGER, 2019; VERGER; NOVELLI; ALTINYELKEN, 2018). Esse fator condiciona a capacidade dos vários países para "conduzir os seus sistemas educacionais" (BALL, 2012, p. 138).

Tendo presente esses pressupostos, optamos por analisar os fluxos financeiros de 2011 a 2020 para a Parceria Global para a Educação (PGE), uma vez que esse é considerado o fundo internacional mais importante de apoio aos países do Sul Global, em especial os países da África Subsaariana. A PGE reúne 70 países do Sul Global e mais de 20 doadores e declarase como a única parceria multilateral e o único fundo dedicado a que todas as crianças e todos os jovens do Sul Global tenham acesso à escola de modo a receberem educação de qualidade, disponibilizando mais de $60 \%$ do seu financiamento para os países frágeis ou afetados por conflito (GLOBAL PARTNERSHIP FOR EDUCATION, 2019a). Apesar de haver a participação de toda essa tipologia de instituições, o Banco Mundial ou o UNICEF (Fundo das Nações Unidas para a Infância) assumem, na maioria dos casos, um papel de destaque.

Foram analisados relatórios e dados estatísticos disponibilizados pela PGE no seu sítio da internet (https://www.globalpartnership.org). O tratamento e análise do corpus documental obedeceu a uma estratégia indutiva que visou responder às questões: quem são os doadores, que financiamento disponibilizam e em que ano(s)? Numa primeira fase, procedemos à identificação exaustiva dos atores que fornecem apoio financeiro à Parceria Global para a Educação e à sua categorização, conforme a tipologia definida por Menashy \& Shields (2017). Numa segunda fase, conduzimos uma estatística descritiva para identificar e categorizar os doadores mediante o volume de doações, tendo em consideração os anos civis em que o fizeram.

O presente artigo encontra-se organizado em quatro partes. Na primeira, tecemos algumas considerações sobre as políticas educacionais globais e como a PGE se enquadra nesse processo. $\mathrm{Na}$ segunda, expomos a abordagem metodológica. $\mathrm{Na}$ terceira, apresentamos e discutimos os dados. Por fim, na quarta parte, intitulada Considerações Finais, identificamos as principais conclusões.

\section{A Parceria Global para a Educação e as Políticas Educacionais Globais}

A PGE é uma parceria multi-stakeholders ${ }^{1}$ criada em 2002, para possibilitar o aumento da colaboração entre o setor público e o privado (MENASHY, 2019). O nome Parceria Global para a Educação foi adotado em 2011, após a Education For All Fast Track Initiative ter sido rebatizada e adotada uma nova estrutura de governação. A sua sede é em Washington, nos Estados Unidos da América, nas instalações do Banco Mundial (GLOBAL PARTNERSHIP

1 Uma parceria multi-stakeholders é um fórum para colaboração, coordenação e tomada de decisões que reúne organizações com diferentes tipologias, mandatos e proveniências geográficas (Norte e Sul Globais), incluindo organizações multilaterais, governamentais, da sociedade civil, fundações e empresas privadas (MENASHY, 2019). 
A Parceria Global pela Educação e o Financiamento da Educação

FOR EDUCATION, 2019a). Na tipologia dos fundos, a PGE é considerada um fundo vertical, pois o financiamento que canaliza para os diferentes países é destinado a apoiar apenas o setor da educação. É também considerada uma parceria público-privada, uma vez que inclui na sua estrutura doadores e receptores de ajuda ao desenvolvimento, agências multilaterais, sociedade civil, fundações privadas e empresas, em que todos atuam como parceiros (KNUTSSON; LINDBERG, 2019; MENASHY, 2016; 2019; MENASHY; DRYDENPETERSON, 2015). A PGE é particularmente relevante no financiamento dos países da África-Subsaariana, uma vez que apenas oito, entre os 40 países dessa área geográfica, não são apoiados por esse Fundo (GLOBAL PARTNERSHIP FOR EDUCATION, 2019b).

Nesse contexto, não podemos descurar que o Banco Mundial é, desde os anos 1990, sem dúvida o maior financiador externo e a agência mais influente de políticas em matéria de educação nos países do Sul Global. As decisões são tomadas sem existir o sistema de um país, um voto, para além de possuir atualmente o monopólio como arquiteto das políticas educacionais globais (KLEES, 2012; MUNDY; GREEN; LINGARD; VERGER, 2016). Todo esse processo levou à colonização da educação pela economia, sendo a prevalência da taxa de retorno na agenda de educação para todos um exemplo do poder epistémico do Banco Mundial (ELFERT, 2021)

Posto isso, podemos sem margem de dúvidas considerar que o modelo de parceria associado à PGE é o da globalização econômica neoliberal, que pode ser enquadrada na crescente influência que organizações internacionais e regionais têm nos sistemas educacionais ao redor do mundo (ADRIÃO, 2018; ANDERSON-LEVITT, 2008; CROSO; MAGALHÃES, 2016; RIZVI; LINGARD, 2010; SILVA; SANTOS; PACHECO, 2015; VERGER; NOVELLI; ALTINYELKEN, 2012). Dessa forma, os atores privados têm legitimidade na PGE, muito mais relacionada a fatores discursivos e crenças do que na sua contribuição financeira e sua capacidade de governança e/ou promoção de inovações. As motivações para esses atores privados participarem dessas parcerias está mais relacionada com a promoção das suas agendas, orientadas pelo lucro, bem como com a estratégia de solidificar a relação com atores que tenham a capacidade de implementar as suas iniciativas (KNUTSSON; LINDBERG, 2019; MENASHY, 2016; 2019). Esses processos permitem que líderes empresariais estejam cada vez mais no centro das parcerias multi-stakeholders, assumindo o papel de especialistas em políticas educacionais globais, envolvendo-se na formulação de políticas, por serem considerados detentores de competências como criatividade, eficiência, inovação e capacidades financeiras ilimitadas (MENASHY, 2016; 2019; MENASHY; DRYDEN-PETERSON, 2015).

Nesse tipo de parcerias podemos encontrar novos atores, que podem ser atores privados transnacionais, organizações de investigação e policy entrepreneurs que constroem, criam e implementam políticas educacionais no âmbito das fronteiras nacionais, influenciando a forma como certas políticas e/ou reformas educacionais são selecionadas, implementadas e avaliadas. Tal processo pode ser considerado a quinta era da filantropia, em que os filantropos são bilionários globais, particularmente relacionados com as tecnologias de informação e comunicação e dos mercados financeiros (BISHOP; GREEN, 2008). Uma vez que a gestão e a forma como fazem as suas doações estão relacionadas com a forma como gerem as suas empresas, são conhecidos como filantropia de risco, uma vez que um dos objetivos é assegurar que o investimento social gere resultados e atraia novos investidores 
A Parceria Global pela Educação e o Financiamento da Educação

para a causa. As suas motivações estão relacionadas com a resolução de grandes problemas mundiais (BISHOP; GREEN, 2008).

Assim, a política educacional tal como a conhecíamos, mas também a forma como a pensamos e estudamos, foi alterada, uma vez que organizações como, por exemplo, organizações multilaterais, organizações não governamentais, agências governamentais e fundações não são órgãos externos ao Estado, são mais externas a uns Estados do que a outros e são agentes políticos relevantes na governança da educação (ROBERTSON, 2012; VERGER; NOVELLI; ALTINYELKEN, 2012). Dessa forma, a "[...] a delimitação entre as esferas pública e privada nos processos de política parece ser cada vez mais difícil de estabelecer. O setor corporativo opera não apenas como um influenciador de políticas, mas como um ator que está cada vez mais inserido nos processos de formulação de políticas" (FONTDEVILA; VERGER; AVELAR, 2019, p. 11, tradução nossa)².

Os discursos formulados por diferentes instituições internacionais circulam pelas diferentes organizações, assim como, posteriormente, por ministérios e outros atores nacionais, observando-se que atuam ao nível da gestão da educação, da oferta educacional e do currículo (ADRIÃO, 2018; MUNDY; GREEN; LINGARD; VERGER, 2016). Esse processo torna o espaço político um mercado de ideias, de discursos e de práticas em que agentes externos têm uma grande capacidade material e ideológica para definir agendas e prioridades, principalmente nos países periféricos e semiperiféricos (ROBERTSON; MUNDY; VERGER; MENASHY, 2012; VERGER; NOVELLI; ALTINYELKEN, 2012; 2018).

$\mathrm{Na}$ atualidade, e tendo em consideração esse contexto, não há dúvida de que as políticas educacionais globais serviram de catalisador para a introdução de novos discursos, práticas e agendas, sendo os agentes de produção e circulação desses discursos diversificados. Não obstante, não devemos descurar que há uma tensão entre processos hegemônicos e contra-hegemônicos que provocam avanços e recuos, contestações e fontes de resistência (VERGER; STEINER-KHAMSI; LUBIENSKI, 2017). Essas tensões estão relacionadas com o fato de que os atores nacionais dos países periféricos e semiperiféricos não são passivos e podem desempenhar um papel duplo nesse diálogo global, sendo, ao mesmo tempo, agentes de emancipação e de regulação (GEORGE; LEWIS, 2012; KASSAYE, 2013; LE GRANGE, 2013; MACPHERSON, 2016).

Apear de assistirmos à presença de uma multiplicidade de atores no seio da PGE, há alguns que têm maior influência e uma voz dominante na tomada de decisões, uma vez que predomina o poder estrutural que dá preponderância a certos atores em detrimento de outros mediante sua posição numa hierarquia, nesse caso os doadores têm maior poder (MENASHY, 2018; 2019). Um outro aspeto que reforça esse poder do Norte Global é o predomínio do inglês como língua de trabalho (MENASHY, 2017; 2018; 2019). Apesar de existirem autores (SACK, 2020) que referem que essa arquitetura de financiamento permitiu diversificar o financiamento da educação, acabando o Banco Mundial por deixar de concentrar a definição de agendas e liderança, parece-nos que esse processo acaba por acontecer apenas em parte, uma vez que os países continuam a ter grilhões em forma de Planos Setoriais da Educação (SILVA; OLIVEIRA, 2020). Esse aspeto advém do fato de esses Planos terem de seguir as

2 No original em inglês: [...] delimitation between the public and the private spheres in policy processes seems to be increasingly difficult to establish The corporate sector operates not only as a policy influencer, but as an actor that is increasingly embedded within policymaking processes. 
A Parceria Global pela Educação e o Financiamento da Educação

linhas orientadoras da PEG e sofrerem uma forte influência dos doadores presentes nos países e dos consultores contratados para apoiar a sua elaboração/avaliação, que segue, obrigatoriamente, as orientações da PEG (MENASHY, 2017; 2019; MENASHY; DRYDENPETERSON, 2015). Se esses planos não forem considerados robustos, os países não recebem o apoio financeiro.

Por fim, o caso exposto por Elfert (2021) sobre o Co-operative Program que ocorreu entre a Organização das Nações Unidas para a Educação, a Ciência e a Cultura (UNESCO) e o Banco Mundial, no período de 1964-1989, e a forma como este exerceu o seu poder epistémico pode ser útil para analisar a PGE, à medida que continuamos a observar mudanças na governança global e nas lutas pela autoridade sobre a educação. Esse aspeto é exacerbado pela predominância no setor da educação em termos globais das questões inerentes às medições globais da "aprendizagem" (GREK, 2020), e pela arquitetura de governança ambiciosa assumida pela PGE para tentar fabricar/falsificar consensos. Esse último aspeto está relacionado com o uso pela PEG do argumento de que as suas decisões são apenas baseadas na ciência, nas evidências científicas, e nas boas práticas, para assim as questões políticas ficarem reféns de atores externos, supostamente neutros. Assim, tais estratégias permitem que a PGE despolitize o seu trabalho (KNUTSSON; LINDBERG, 2020). A esse respeito, devemos também ter em consideração que a retórica das decisões baseadas em evidências é muitas vezes utilizada com base em investigação superficial, ou com resultados contestados, ou parciais, ou de um único caso e/ou apenas com um enquadramento ideológico (PARREIRA DO AMARAL; STEINER-KHAMSI; THOMPSON, 2019).

\section{Metodologia}

O presente artigo tem por base uma análise documental (documentos primários) que permita perceber os fluxos de doações para a Parceria Global para a Educação, no período de 2011 a 2020, enquanto um caso elucidativo da problemática do financiamento da educação nos países do Sul Global, principalmente os países da África Subsaariana, uma vez que esse fundo tem um papel preponderante no apoio ao setor da educação nos países dessa área geográfica. Esse tipo de análise foi utilizada por se tratar de uma técnica não interferente nos estudos de ciências sociais (LEE, 2003).

Os documentos primários usados (corpus documental) são compostos por relatórios e dados estatísticos disponibilizados pela Parceria Global para a Educação no seu sítio da internet e refletem informações sobre o período de 2011 a 2020. Contatamos o Chief Financial Officer e o Financial Officer da PGE via correio eletrônico que se disponibilizaram a enviar informações complementares às disponibilizadas no sítio da Internet. Contudo, até ao momento de submissão do presente artigo os dados ainda não haviam sido disponibilizados. O tratamento e análise do corpus documental obedeceu a uma estratégia indutiva que visou responder às questões: quem são os doadores, que financiamento disponibilizam e em que ano(s)?

A PGE foi selecionada para o presente estudo pelo papel preponderante que tem no apoio ao setor da educação aos países do Sul Global, em particular aos países frágeis e afetados por conflito. 
A Parceria Global pela Educação e o Financiamento da Educação

Numa primeira fase, procedemos à identificação exaustiva dos atores que fornecem apoio financeiro à PGE e à sua categorização conforme a sua tipologia, seguindo a seguinte categorização, definida por Menashy \& Shields (2017):

- Organizações da Sociedade Civil ou Organizações Não governamentais: inclui organizações ligadas diretamente à implementação de programas no setor da educação nos países do Sul Global. Essa categoria inclui também campanhas e redes de advocacia;

- Doadores bilaterais internacionais: inclui os diferentes países que fornecem ajuda pública ao desenvolvimento. Nessa classificação estão incluídos os apoios de organizações como, por exemplo, Agência dos Estados Unidos para o Desenvolvimento Internacional e a Agência Norueguesa de Cooperação para o Desenvolvimento;

- Organizações Internacionais: inclui organizações cujos membros são Estados Nação (UNICEF; Banco Mundial). Essa categoria inclui também organizações multilaterais de desenvolvimento (Programa das Nações Unidas para o Desenvolvimento; Comissão Europeia);

- Governos receptores de ajuda ao desenvolvimento: inclui governos de países do Sul Global que são elegíveis para receber ajuda ao desenvolvimento, como, por exemplo, a Guiné-Bissau, a Tanzânia e a Bolívia;

- Fundações Privadas: inclui qualquer doador de ajuda ao desenvolvimento que não seja um governo nacional, mas que tenha por objetivo principal financiar outras organizações, como, por exemplo, a Fundação Aga Khan e a Open Society Foundation;

- Empresas Privadas: inclui organizações como, por exemplo, Accenture, Cisco e a Chevron;

- Universidades e Institutos de Investigação: inclui organizações que têm por missão atividades de investigação e não implementam programas, como, por exemplo, a Universidade de Sussex e a Brookings Institution.

Um tipo de financiamento que a PGE recebe e não se enquadra nessa tipologia são as taxas de retorno de investimento que resultam de investimentos em bolsa.

Numa segunda fase, conduzimos uma estatística descritiva para identificar e categorizar os doadores mediante o volume de doações, tendo em consideração os anos civis em que o fizeram e tomando por base os dados retirados dos vários documentos consultados. Procedemos também à identificação da sede de cada uma das organizações para perceber em que continente se situam.

\section{Análise e Discussão dos Dados}

Da análise da Tabela 1 podemos considerar que o número de doadores por ano civil estabiliza no período de 2011 a 2017, com uma média de 17 doadores por ano, aumentando nos anos de 2017, 2018 e 2019, para decrescer em 2020. 
A Parceria Global pela Educação e o Financiamento da Educação

Tabela 1 - Número de doadores por ano civil e valor total de fundos recebido

\begin{tabular}{ccc}
\hline Ano & $\begin{array}{c}\text { Número total de } \\
\text { doadores }\end{array}$ & $\begin{array}{c}\text { Valor total de fundos } \\
\text { recebidos em dólares } \\
\text { americanos }\end{array}$ \\
\hline 2011 & 16 & 409454 498,91 USD \\
2012 & 16 & 504338727,68 USD \\
2013 & 16 & 390054832,01 USD \\
2014 & 17 & 553175808,28 USD \\
2015 & 17 & 251137191,42 USD \\
2016 & 16 & 467794420,35 USD \\
2017 & 19 & 473645921,97 USD \\
2018 & 23 & 637613076,27 USD \\
2019 & 20 & 565842919,45 USD \\
2020 & 14 & 491370245,03 USD \\
\hline
\end{tabular}

Fonte: Elaboração dos autores com base nos dados disponibilizados pela PGE.

Observamos ainda que, embora o valor total de fundos disponíveis oscile, com a exceção dos anos de 2013, 2015 e 2020, o montante total aumenta de um ano para o seguinte, sendo a maior parte desse valor canalizado para apoiar o setor da educação nos países da África Subsaariana. Esse aspeto está relacionado com o facto de que há 86 países elegíveis para receber apoio da PEG e, destes, 20 não recebem qualquer apoio, uma vez que não solicitaram adesão à PEG. Assim, dos 66 países que recebem apoio financeiro atualmente da PGE, 32 situam-se na África Subsaariana, estando os restantes 34 distribuídos pela América Central, América do Sul, Ásia e Oceania.

É possível também observar que a oscilação no número total de doadores não tem uma relação direta com o volume de fundos disponibilizados (Tabela 2), uma vez que o valor total de fundos aumenta ou diminui de forma independente do número total de doadores. Dessa forma, esses dados parecem indicar que os fundos disponibilizados estão mais dependentes do valor que os doares individualmente disponibilizam em cada ano civil do que do número total de doadores. Essa percepção é confirmada, por exemplo, se analisarmos em maior profundidade os fluxos dos três principais doadores da PGE no período em análise, Reino Unido, Noruega e Dinamarca (Tabelas 3 e 4), de modo que o valor total disponibilizado em dólares americanos vária de ano para ano, umas vezes diminuindo outras aumentando. 
Tabela 2 - Percentagem de financiamento do PGE por doador, por ano civil

\begin{tabular}{|c|c|c|c|c|c|c|c|c|c|c|c|}
\hline Doador & 2011 & 2012 & 2013 & 2014 & 2015 & 2016 & 2017 & 2018 & 2019 & 2020 & Total \\
\hline Alemanha & $1,75 \%$ & $1,52 \%$ & $2,39 \%$ & $1,56 \%$ & $3,06 \%$ & $1,65 \%$ & $1,67 \%$ & $3,24 \%$ & $7,21 \%$ & $2,09 \%$ & $2,70 \%$ \\
\hline Austrália & $3,14 \%$ & $16,11 \%$ & $7,86 \%$ & $27,42 \%$ & $19,66 \%$ & $4,24 \%$ & $5,7 \%$ & $1,83 \%$ & $0 \%$ & $7,07 \%$ & $8,83 \%$ \\
\hline Bélgica & $1,99 \%$ & $2,37 \%$ & $2,97 \%$ & $1,56 \%$ & $4,82 \%$ & $1,49 \%$ & $1,62 \%$ & $1,26 \%$ & $1,29 \%$ & $0 \%$ & $1,73 \%$ \\
\hline Canadá & $0,05 \%$ & $9,05 \%$ & $0 \%$ & $0 \%$ & $9,37 \%$ & $4,8 \%$ & $4,72 \%$ & $3,81 \%$ & $3,95 \%$ & $15,01 \%$ & $4,94 \%$ \\
\hline $\begin{array}{l}\text { Comissão } \\
\text { Europeia }\end{array}$ & $0,96 \%$ & $4,05 \%$ & $0,8 \%$ & $6,6 \%$ & $0 \%$ & $7,7 \%$ & $24,99 \%$ & $23,01 \%$ & $0 \%$ & $0 \%$ & $7,69 \%$ \\
\hline Dinamarca & $12,62 \%$ & $12,68 \%$ & $13,06 \%$ & $10,54 \%$ & $16,07 \%$ & $3,07 \%$ & $8,1 \%$ & $8,9 \%$ & $7,95 \%$ & $12,11 \%$ & $10,10 \%$ \\
\hline $\begin{array}{l}\text { Dubai Cares } \\
\text { (Fundação) } \\
\end{array}$ & $0 \%$ & $0 \%$ & $0 \%$ & $0 \%$ & $0 \%$ & $0 \%$ & $0,21 \%$ & $0,08 \%$ & $0,09 \%$ & $0 \%$ & $0,04 \%$ \\
\hline $\begin{array}{l}\text { Émirados } \\
\text { Árabes Unidos }\end{array}$ & $0 \%$ & $0 \%$ & $0 \%$ & $0 \%$ & $0 \%$ & $0 \%$ & $0 \%$ & $3,88 \%$ & $1,46 \%$ & $6,72 \%$ & $1,39 \%$ \\
\hline Espanha & $0 \%$ & $0 \%$ & $6,88 \%$ & $0 \%$ & $0 \%$ & $0 \%$ & $0 \%$ & $0 \%$ & $0,18 \%$ & $0,13 \%$ & $0,60 \%$ \\
\hline $\begin{array}{l}\text { Estados } \\
\text { Unidos da } \\
\text { América }\end{array}$ & $0 \%$ & $0,16 \%$ & $5,39 \%$ & $3,65 \%$ & $15,93 \%$ & $24,58 \%$ & $0 \%$ & $11,76 \%$ & $15,46 \%$ & $18,32 \%$ & $9,47 \%$ \\
\hline Finlândia & $0 \%$ & $0 \%$ & $0 \%$ & $0,8 \%$ & $1,25 \%$ & $0 \%$ & $0 \%$ & $0 \%$ & $0 \%$ & $0 \%$ & $0,16 \%$ \\
\hline França & $5,50 \%$ & $4,16 \%$ & $5,9 \%$ & $0 \%$ & $0,42 \%$ & $1,8 \%$ & $1,84 \%$ & $4,73 \%$ & $10,11 \%$ & $14,44 \%$ & $5,12 \%$ \\
\hline $\begin{array}{l}\text { Fundação } \\
\text { Children's } \\
\text { Investment } \\
\text { Fund } \\
\end{array}$ & $0 \%$ & $0 \%$ & $0 \%$ & $0,9 \%$ & $0 \%$ & $0 \%$ & $0,21 \%$ & $0,31 \%$ & $0 \%$ & $0 \%$ & $0,17 \%$ \\
\hline $\begin{array}{l}\text { Fundação } \\
\text { Rockefeller }\end{array}$ & $0 \%$ & $0 \%$ & $0 \%$ & $0 \%$ & $0 \%$ & $0,07 \%$ & $0 \%$ & $0 \%$ & $0 \%$ & $0 \%$ & $0,01 \%$ \\
\hline Irlanda & $1,24 \%$ & $1,03 \%$ & $1,78 \%$ & $0,75 \%$ & $1,77 \%$ & $0,93 \%$ & $1 \%$ & $1,89 \%$ & $1,47 \%$ & $1,62 \%$ & $1,33 \%$ \\
\hline Itália & $0,52 \%$ & $0,31 \%$ & $0,52 \%$ & $0,32 \%$ & $0,66 \%$ & $0,91 \%$ & $0,5 \%$ & $0,74 \%$ & $0,78 \%$ & $0 \%$ & $0,53 \%$ \\
\hline Japão & $0,18 \%$ & $1,07 \%$ & $1,3 \%$ & $0,53 \%$ & $0,97 \%$ & $0,32 \%$ & $0,41 \%$ & $0,28 \%$ & $0,57 \%$ & $0,17 \%$ & $0,54 \%$ \\
\hline Luxemburgo & $0,25 \%$ & $0 \%$ & $0 \%$ & $0,07 \%$ & $0,13 \%$ & $0 \%$ & $0 \%$ & $0,06 \%$ & $0,3 \%$ & $0 \%$ & $0,08 \%$ \\
\hline Noruega & $9,43 \%$ & $6,75 \%$ & $10,14 \%$ & $7,35 \%$ & $17,92 \%$ & $12,43 \%$ & $16,17 \%$ & $12,11 \%$ & $14,52 \%$ & $12,07 \%$ & $11,62 \%$ \\
\hline $\begin{array}{l}\text { Open Society } \\
\text { Foundation }\end{array}$ & $0 \%$ & $0 \%$ & $0,00 \%$ & $0 \%$ & $0 \%$ & $0 \%$ & $0,11 \%$ & $0,16 \%$ & $0 \%$ & $0 \%$ & $0,03 \%$ \\
\hline Países Baixos & $9,57 \%$ & $7,85 \%$ & $10,57 \%$ & $6,76 \%$ & $0 \%$ & $0 \%$ & $0 \%$ & $8,91 \%$ & $2,01 \%$ & $0 \%$ & $4,76 \%$ \\
\hline Reino Unido & $38,24 \%$ & $28,66 \%$ & $24,76 \%$ & $14,15 \%$ & $0 \%$ & $29,24 \%$ & $21,53 \%$ & $5,4 \%$ & $25,12 \%$ & $0 \%$ & $18,79 \%$ \\
\hline $\begin{array}{l}\text { República da } \\
\text { Coréia }\end{array}$ & $0 \%$ & $0 \%$ & $0 \%$ & $0 \%$ & $0,56 \%$ & $0,15 \%$ & $0,15 \%$ & $0,11 \%$ & $0,12 \%$ & $0,16 \%$ & $0,11 \%$ \\
\hline Romênia & $0,05 \%$ & $0 \%$ & $0 \%$ & $0 \%$ & $0 \%$ & $0 \%$ & $0 \%$ & $0 \%$ & $0 \%$ & $0 \%$ & $0,004 \%$ \\
\hline Rússia & $0,49 \%$ & $0 \%$ & $0 \%$ & $0 \%$ & $0 \%$ & $0,00 \%$ & $0,00 \%$ & $0 \%$ & $0 \%$ & $0 \%$ & $0,04 \%$ \\
\hline $\begin{array}{l}\text { Stichting } \\
\text { Benevolentia } \\
\text { (Fundação) }\end{array}$ & $0,00 \%$ & $0 \%$ & $0 \%$ & $0 \%$ & $0 \%$ & $0,00 \%$ & $0,18 \%$ & $0,13 \%$ & $0,1 \%$ & $0 \%$ & $0,05 \%$ \\
\hline Suécia & $13,61 \%$ & $2,83 \%$ & $3,89 \%$ & $15,74 \%$ & $4,68 \%$ & $6,61 \%$ & $6,66 \%$ & $5,22 \%$ & $5,55 \%$ & $6,6 \%$ & $7,24 \%$ \\
\hline Suiça & $0,40 \%$ & $1,4 \%$ & $1,79 \%$ & $1,3 \%$ & $2,72 \%$ & $0,00 \%$ & $4,23 \%$ & $2,18 \%$ & $1,76 \%$ & $3,5 \%$ & $1,91 \%$ \\
\hline
\end{tabular}

Fonte: Elaboração dos autores com base nos dados disponibilizados pela PGE. 
A Parceria Global pela Educação e o Financiamento da Educação

Tabela 3 - Percentagem de financiamento do PGE em dólares americanos por doador, por ano civil

\begin{tabular}{|c|c|c|c|c|c|}
\hline Doador & 2011 & 2012 & 2013 & 2014 & 2015 \\
\hline Alemanha & 7179975 & 7687350 & 9309860 & 8626100 & 7681905 \\
\hline Austrália & 12856549,87 & 81274000 & 30675000 & 151677000 & 49385700 \\
\hline Bélgica & 8145700 & 11934000 & 11579400 & 8614900 & 12105210 \\
\hline Canadá & 203037,44 & 45620743,45 & 0 & 0 & 23534949 \\
\hline Comissão Europeia & 3931852,41 & 20414010 & 3121983 & 36482080 & 0 \\
\hline Dinamarca & 51670784,38 & 63964429,36 & 50939123 & 58308243 & 40346180 \\
\hline Dubai Cares (Fundação) & 0 & 0 & 0 & 0 & 0 \\
\hline Emirados Árabes Unidos & 0 & 0 & 0 & 0 & 0 \\
\hline Espanha & 0 & 0 & 26826000 & 0 & 0 \\
\hline Estados Unidos da América & 0 & 800000 & 21020000 & 20180000 & 40000000 \\
\hline Finlândia & 0 & 0 & 0 & 4399315 & 3149454 \\
\hline França & 22518166,2 & 20977332,49 & 23031835 & 0 & 1066200 \\
\hline $\begin{array}{l}\text { Fundação Children's Investment } \\
\text { Fund }\end{array}$ & 0 & 0 & 0 & 5000000 & 0 \\
\hline Fundação Rockefeller & 0 & 0 & 0 & 0 & 0 \\
\hline Irlanda & 5095350,01 & 5202400 & 6929400 & 4155900 & 4440800 \\
\hline Itália & 2133300 & 1586280,01 & 2024100 & 1796798 & 1665300 \\
\hline Japão & 741600 & 5400000 & 5070000 & 2910000 & 2442000 \\
\hline Luxemburgo & 1006040 & 0 & 0 & 410160 & 334050 \\
\hline Noruega & 38631047,28 & 34053230,58 & 39533186 & 40665632 & 45000242 \\
\hline Open Society Foundation & 0 & 0 & 0 & 0 & 0 \\
\hline Países Baixos & 39204000 & 39600000 & 41232000 & 37422000 & 0 \\
\hline Reino Unido & 156571796 & 144522320 & 96587000 & 78270000 & 0 \\
\hline República da Coréia & 0 & 0 & 0 & 0 & 1400000 \\
\hline Romênia & 199832,5 & 0 & 0 & 0 & 0 \\
\hline Rússia & 2000000 & 0 & 0 & 0 & 0 \\
\hline Stichting Benevolentia (Fundação) & 0 & 0 & 0 & 0 & 0 \\
\hline Suécia & 55735033,04 & 14259029,53 & 15178422 & 87069006 & 11758186 \\
\hline Suíça & 1630434,78 & 7043602,26 & 6997524 & 7188675 & 6827014 \\
\hline
\end{tabular}

Fonte: Elaboração dos autores com base nos dados disponibilizados pela PGE. 
A Parceria Global pela Educação e o Financiamento da Educação

Tabela 4 - Percentagem de financiamento do PGE em dólares americanos por doador, por ano civil (cont.)

\begin{tabular}{|c|c|c|c|c|c|}
\hline Doador & 2016 & 2017 & 2018 & 2019 & 2020 \\
\hline Alemanha & 7716799,99 & 7928900 & 20651335 & 40809302,79 & 10278360 \\
\hline Austrália & 19811600 & 27000299,99 & 11660800 & 0 & 34741975 \\
\hline Bélgica & 6975625 & 7653750 & 8010795 & 7274110,88 & 0 \\
\hline Canadá & 22456753,91 & 22373366,74 & 24297656 & 22368512,29 & 73741630 \\
\hline Comissão Europeia & 36006299,99 & 118356262,5 & 146745652,7 & 0 & 0 \\
\hline Dinamarca & 14380228,5 & 38367225,11 & 56725189 & 44987628,4 & 59509217 \\
\hline Dubai Cares (Fundação) & 0 & 1000000 & 500000 & 500000 & 0 \\
\hline Emirados Árabes Unidos & 0 & 0 & 24749940 & 8249940 & 32999932 \\
\hline Espanha & 0 & 0 & 0 & 1022493,95 & 626546,1 \\
\hline Estados Unidos da América & 115000000 & 0 & 75000000 & 87500000 & 90000000 \\
\hline Finlândia & 0 & 0 & 0 & 0 & 0 \\
\hline França & 8435600 & 8728300 & 30157180 & 57219936 & 70971394 \\
\hline $\begin{array}{l}\text { Fundação Children's Investment } \\
\text { Fund }\end{array}$ & 0 & 1000000 & 2000000 & 0 & 0 \\
\hline Fundação Rockefeller & 350000 & 0 & 0 & 0 & 0 \\
\hline Irlanda & 4365600 & 4718400 & 12076380 & 8303249,99 & 7957250 \\
\hline Itália & 4260400 & 2381100 & 4705120 & 4406800 & 0 \\
\hline Japão & 1474481 & 1933716 & 1761790 & 3224437 & 828780 \\
\hline Luxemburgo & 0 & 0 & 372000 & 1680752,51 & 0 \\
\hline Noruega & 58140655,25 & 76593228,65 & 77201734 & 82149375,57 & 59291715 \\
\hline Open Society Foundation & 0 & 500000 & 1000000 & 0 & 0 \\
\hline Países Baixos & 0 & 0 & 56818182 & 11363635,18 & 0 \\
\hline Reino Unido & 136799050 & 101990800 & 34430400 & 142139200 & 0 \\
\hline República da Coréia & 700000 & 700000 & 700000 & 700000 & 800000 \\
\hline Romênia & 0 & 0 & 0 & 0 & 0 \\
\hline Rússia & 0 & 0 & 0 & 0 & 0 \\
\hline Stichting Benevolentia (Fundação) & 0 & 850000 & 850000 & 539975 & 0 \\
\hline Suécia & 30921326,71 & 31546028,74 & 33299065 & 31418547,42 & 32436711 \\
\hline Suíça & 0 & 20024544,25 & 13899857 & 9985022,47 & 17186735 \\
\hline
\end{tabular}

Fonte: Elaboração dos autores com base nos dados disponibilizados pela PGE.

Os dados presentes na tabela 5 permitem perceber que a PGE também conta com fundos provenientes de investimentos em bolsa, tal como o Banco Mundial, obtendo anualmente taxas de retorno do investimento que reverte para a PGE. Esses fundos representam aproximadamente $2 \%$ do orçamento dos anos em que temos dados disponíveis, 2017, 2018 e 2019. 
A Parceria Global pela Educação e o Financiamento da Educação

Tabela 5 - Taxas de retorno de investimento por ano e respetiva percentagem do orçamento anual

\begin{tabular}{ccc}
\hline Ano & $\begin{array}{c}\text { Valor total de fundos } \\
\text { recebidos em dólares } \\
\text { americanos }\end{array}$ & \% do orçamento anual \\
\hline 2011 & Não disponível & \\
2012 & Não disponível & \\
2013 & Não disponível & \\
2014 & Não disponível & \\
2015 & Não disponível & \\
2016 & Não disponível & $2,39 \%$ \\
2017 & 107 milhões de USD & $2,35 \%$ \\
2018 & 116,6 milhões de USD & $2,36 \%$ \\
2019 & 132,7 milhões de USD & \\
2020 & Não disponível & \\
\hline
\end{tabular}

Fonte: Elaboração dos autores com base nos dados disponibilizados pela PGE.

A análise da Tabela 5 permite constatar que, se organizarmos os doadores por continente, temos 4 na América do Norte, 4 na Ásia, 18 na Europa, 1 na Eurásia (apesar de não ser um continente classificamos dessa forma porque a Rússia tem território em dois continentes) e 1 doador na Oceania. Os países europeus que fazem parte da União Europeia ${ }^{3}$ acabam, de forma indireta, por contribuir todos para a PGE através do orçamento da Comissão Europeia. Dessa maneira, há países que contribuem duas vezes, uma de forma direta e outra indireta. Esses dados permitem também constatar que a maior contribuição para a PGE vem da Europa, muito provavelmente associada à percentagem do rendimento nacional bruto que os países desse continente dedicam à ajuda pública ao desenvolvimento e ao apoio prioritário que dão ao setor da educação. Por exemplo, os Estados Unidos da América e o Canadá disponibilizaram em 2019 para ajuda pública ao desenvolvimento, respetivamente, $0,154 \%$ e $0,275 \%$ do seu Rendimento Nacional Bruto e, o Reino Unido a Dinamarca e a Noruega, $0,704 \%, 0,717 \%$ e 1,026\% (OCDE, 2020). Essa percepção é confirmada pelo facto identificado anteriormente, quando verificamos que os fundos disponíveis pela PGE anualmente estão mais dependentes do valor que os doares individualmente disponibilizam em cada ano civil do que do número total de doadores.

Em relação às Fundações, mesmo havendo na América do Norte uma maior tradição desse tipo de organizações, vemos que a contribuição mais expressiva vem novamente da Europa, com $0,22 \%$ do financiamento no período em análise, contra $0,04 \%$ de organizações da América do Norte.

3 No período em análise a União Europeia ainda era constituída por 28 países: Alemanha, Áustria, Bélgica, Bulgária, Chipre, Croácia, Dinamarca, Eslováquia, Eslovénia, Espanha, Estónia, Finlândia, França, Grécia, Holanda, Hungria, Irlanda, Itália, Letónia, Lituânia, Luxemburgo, Malta, Polónia, Portugal, Reino Unido, Républica Checa, Roménia e Suécia. 
A Parceria Global pela Educação e o Financiamento da Educação

Tabela 6 - Doadores organizados por continente e percentagem total de financiamento da PGE no período de 2011 a 2020

\begin{tabular}{|c|c|}
\hline & Total em \% \\
\hline América do Norte & $14,46 \%$ \\
\hline Canada & $4,94 \%$ \\
\hline Estados Unidos da América & $9,47 \%$ \\
\hline Fundação Rockefeller & $0,01 \%$ \\
\hline Open Society Foundation & $0,03 \%$ \\
\hline Ásia & $2,08 \%$ \\
\hline Dubai Cares & $0,04 \%$ \\
\hline Emirados Árabes Unidos & $1,39 \%$ \\
\hline Japão & $0,54 \%$ \\
\hline República da Coréia & $0,11 \%$ \\
\hline Eurásia & $0,04 \%$ \\
\hline Rússia & $0,04 \%$ \\
\hline Europa & $74,58 \%$ \\
\hline Alemanha & $2,70 \%$ \\
\hline Bélgica & $1,73 \%$ \\
\hline Comissão Europeia & $7,69 \%$ \\
\hline Dinamarca & $10,10 \%$ \\
\hline Espanha & $0,60 \%$ \\
\hline Finlândia & $0,16 \%$ \\
\hline França & $5,12 \%$ \\
\hline Fundação Children's Investment Fund & $0,17 \%$ \\
\hline Irlanda & $1,33 \%$ \\
\hline Itália & $0,53 \%$ \\
\hline Luxemburgo & $0,08 \%$ \\
\hline Noruega & $11,62 \%$ \\
\hline Países Baixos & $4,76 \%$ \\
\hline Reino Unido & $18,79 \%$ \\
\hline Romênia & $0,004 \%$ \\
\hline Stichting Benevolentia & $0,05 \%$ \\
\hline Suécia & $7,24 \%$ \\
\hline Suíça & $1,91 \%$ \\
\hline Oceania & $8,83 \%$ \\
\hline Austrália & $8,83 \%$ \\
\hline
\end{tabular}

Fonte: Elaboração dos autores com base nos dados disponibilizados pela PGE.

Os dados permitem constatar que a principal fonte de financiamento da PGE provém de doadores Bilaterais Internacionais, isto é, dos contribuintes desses Estados, seguida pelas Organizações Internacionais, nesse caso a Comissão Europeia, fundos também provenientes dos contribuintes da União Europeia, e por fim pelas Fundações privadas. Não obstante, nos 
A Parceria Global pela Educação e o Financiamento da Educação

anos de 2017, 2018 e 2019 verificamos que aproximadamente $2 \%$ do orçamento total da PGE proveio de investimentos em bolsa.

Quando nos debruçamos sobre uma análise do corpus documental, podemos observar que no período em análise, 2011 a 2020, e tendo em consideração a categorização de Menashy \& Shields (2017), surgem 28 doadores que podem ser incluídos em três categorias - doadores bilaterais internacionais (22), organizações internacionais (1) e fundações privadas (5).

Em termos absolutos, no período de 2011 a 2020, observamos que se destacam três doadores bilaterais internacionais como os principais doadores desse Fundo - Reino Unido, Noruega e Dinamarca. Esses países também se destacam em nível global por serem os países que em percentagem do rendimento nacional bruto mais ajuda pública ao desenvolvimento disponibilizam (OCDE, 2020). A análise permitiu, ainda, constatar que aparecem como doadores Fundações, embora a sua contribuição seja esporádica e inconsistente ao longo dos anos, principalmente concentradas nos anos de 2017 e 2018.

A análise documental mostra que há vários atores, essencialmente empresas privadas, que apoiam a PGE, mas que não figuram nos relatórios de financiamento com nenhuma contribuição. Isso acontece uma vez que essas entidades não contribuem em termos financeiros para suprir as necessidades de financiamento da PEG, mas fornecem apoio em espécie. Um exemplo é a parceria com a Microsoft e a Fundação ligada à empresa Tableau, que apoiam questões relacionadas com os sistemas de informação de gestão da educação, fornecendo apoio através da disponibilização dos seus técnicos e cientistas de forma voluntária. A análise documental também mostra que, com a crise de COVID-19, as parcerias com o setor privado estão mais relacionadas com o fornecimento de ferramentas e formação gratuitas para apoiar o ensino a distância e expandir a conectividade a comunidades que se encontram em áreas remotas.

Apesar de essas iniciativas serem positivas e permitirem encontrar soluções imediatas para desafios que se colocam ao setor da educação, possuem também, na nossa perspectiva, características que podem, em médio ou longo prazo, ser negativas. Esse aspeto está relacionado com o apoio prestado por essas empresas estar ligado às suas áreas de negócio, em detrimento de um apoio financeiro para um fundo que contribua para suprir todas as prioridades dos diferentes países. Um outro aspeto que esse tipo de apoio pode ter incorporado está relacionado com a introdução de softwares e outras soluções tecnológicas que a médio/ longo prazo deixam os utilizadores dependentes de comprar as licenças às empresas que as produzem e do seu apoio técnico, estratégia comumente utilizada pelo setor privado no lançamento de novos produtos. Um outro fator que deve ser tido em consideração é o facto de que muitas dessas Fundações realizam contribuições generosas para várias causas para "limpar" a reputação dos seus fundadores e/ou gestores, transformando-os em generosos benfeitores da humanidade. Tudo isso, enquanto beneficiam de uma ausência de justiça fiscal e as empresas têm práticas em que ativamente fazem fuga aos impostos (LARSON, 2020; MAZZUCATO, 2019). Por fim, as empresas tendem a priorizar o apoio a países e territórios onde fazem negócios, o que pode originar excesso ou falta de serviço às populações que mais necessitam (PARREIRA DO AMARAL; STEINER-KHAMSI; THOMPSON, 2019). 
A Parceria Global pela Educação e o Financiamento da Educação

Esses aspetos coincidem com os apontados por vários autores (KNUTSSON; LINDBERG, 2019; MENASHY, 2016; 2019), quando referem que as motivações para os atores privados participarem nas parcerias como a PGE estão mais relacionadas com a promoção das suas agendas, orientadas pelo lucro, bem como com a estratégia de solidificar a relação com atores que tenham a capacidade de implementar as suas iniciativas. Tudo isso, contudo, não quer dizer que devemos demonizar o setor privado, nem considerar que essas empresas não têm um papel importante a desempenhar. Contudo, não devemos excluir a outra face da moeda e olhar de forma acrítica para os apoios prestados, pois o setor privado deve contribuir para os bens públicos comuns (public good) (MAZZUCATO, 2019).

\section{Considerações Finais}

O artigo buscou analisar o fluxo de doações para a Parceria Global para a Educação (PGE) no período de 2011 a 2020, enquanto um caso elucidativo da problemática do financiamento da educação nos países do Sul Global. Foi realizada uma análise documental de documentos primários compostos por relatórios e dados estatísticos disponibilizados pela Parceria Global para a Educação no seu sítio da internet.

Pôde-se constatar que, globalmente, a PGE no período em análise recebeu apoio de 28 doadores, sendo que, destes, 22 são doadores bilaterais internacionais, um é uma organização internacional e cinco são fundações privadas. Não obstante, os dados disponíveis também permitem perceber que, nos anos de 2017, 2018 e 2019 (não há informação disponível dos restantes anos), a PGE contou com financiamento provenientes taxas de retorno de investimento em bolsa que representaram, aproximadamente, $2 \%$ do orçamento nesses anos.

Os dados apontam também que a PGE é particularmente relevante no financiamento do setor da educação nos países da África Subsaariana, uma vez que 32 dos 40 países dessa área geográfica recebem seu apoio.

Podemos concluir, ainda, que o Reino Unido, a Noruega e a Dinamarca são os principais doadores e que os fluxos provenientes dos contribuintes da União Europeia através de doadores Bilaterais e de Organizações Internacionais representam a maior parte do financiamento, muito provavelmente associado à percentagem do rendimento nacional bruto que os países desse continente dedicam à ajuda pública ao desenvolvimento e à prioridade colocada no setor da educação das políticas de apoio ao desenvolvimento. No que concerne às Fundações privadas, vemos que a sua contribuição é esporádica e inconsistente ao longo dos anos, concentra-se nos anos de 2017 e 2018. Esse apoio financeiro conta novamente com um montante mais expressivo da Europa, representando $0,22 \%$ do financiamento no período em análise, contra $0,04 \%$ de organizações da América do Norte.

$\mathrm{Na}$ categoria empresas privadas, apesar de haver referência ao apoio que estas prestam à PGE (ex. Tableu, Microsoft), não aparecem listadas nos relatórios com o valor da sua contribuição. Esse facto revela que essas empresas privadas apoiam a PGE, mas não em termos financeiros, mas através da disponibilização dos seus técnicos e cientistas de forma voluntária ou pela disponibilização de acesso a plataformas ou softwares. Esse apoio, apesar de permitir o encontro de soluções imediatas para desafios que se colocam ao setor da educação, constitui, ao mesmo tempo, um constrangimento, na medida em que o apoio pode ter incorporado a introdução de softwares e outras soluções tecnológicas que a 
A Parceria Global pela Educação e o Financiamento da Educação

médio/longo prazo deixam os utilizadores dependentes de comprar as licenças às empresas que as produzem e do seu apoio técnico. Contudo, não devemos demonizar o setor privado, não podemos é excluir a outra face da moeda e olhar de forma acrítica para os apoios prestados, uma vez que o setor privado deve contribuir para bens públicos comuns (public good) (MAZZUCATO, 2019) e evitar conflitos de interesses.

Por fim, podemos concluir que no período de 2011 a 2020 a oscilação anual do número total de doadores não tem uma relação direta com o volume de fundos disponibilizados, estando assim esse Fundo mais dependente do fluxo anual de cada doador do que do número de doadores.

Em síntese, o estudo mostra que, no período de 2011 a 2020, as contribuições de países do Norte Global desempenharam um papel crucial no financiamento da educação no Sul Global, principalmente alguns do continente Europeu.

\section{Referências}

ADRIÃO, T. Dimensões e Formas da Privatização da Educação no Brasil: caracterização a partir de mapeamento de produções nacionais e internacionais. Currículo sem Fronteiras, v. 18, n. 1, p. $8-28,2018$.

ANDERSON-LEVITT, K. M. Globalization and Curriculum. In: CONNELLY, F. M.;HE, M. F. et al. (Org.). The SAGE Handbook of Curriculum and Instruction. Londres: SAGE Publications, 2008. p. 349-368.

BALL, S. J. Global education inc: new policy networks and the neo-liberal imaginary. London: Routledge, 2012.

BISHOP, M.; GREEN, M. Philanthrocapitalism. How the Rich Can Save the World. London: Bloomsbury Press, 2008.

CROSO, C.; MAGALHÃES, G. M. Privatização da educação na América Latina e no Caribe: tendências e riscos para os sistemas públicos de ensino. Educação \& Sociedade, Campinas, v. 37, n. 134, p. $17-33,2016$.

ELFERT, M. The power struggle over education in developing countries: The case of the UNESCO-World Bank Co-operative program, 1964-1989. International Journal of Educational Development, n. 81, p. 102336, 2021.

FONTDEVILA, C.; VERGER, A.; AVELAR, M. The business of policy: a review of the corporate sector's emerging strategies in the promotion of education reform. Critical Studies in Education, v. 62, n. 2, p. 131-146, 2021.

GEORGE, J.; LEWIS, T. Exploring the global/local boundary in education in developing countries: the case of the Caribbean. Compare: A Journal of Comparative and International Education, v. 41, n. 6, p. 721-734, 2012.

GLOBAL PARTNERSHIP FOR EDUCATION. Factsheet - August 2019. Global Partnership for Education. 2019a.

GLOBAL PARTNERSHIP FOR EDUCATION. List of GPE partner countries and classification for the purpose of the results framework. 2019b. Disponivel em: 
A Parceria Global pela Educação e o Financiamento da Educação

https://www.globalpartnership.org/sites/default/files/document/file/2020-03-GPE-partnercountries-fragile-conflict.pdf. Acesso em: 02 jun. 2020.

GREK, S. Prophets, saviours and saints: Symbolic governance and the rise of a transnational metrological field. International Review of Education, v. 66, n. 2, p. 139-166, 2020.

KASSAYE, W. Curriculum Development and Research in Ethiopia. In: PINAR, W. F. (Ed.). International Handbook of Curriculum Research. London: Routledge, 2013. p. 161-182.

KLEES, S. J. World Bank and Education. Ideological Premises and Ideological Conclusions. In: KLEES, S. J.;SAMOFF, J. et al. (Org.). The World Bank and education : critiques and alternatives. Rotterdam: Sense Publishers, 2012. p. 49-65.

KNUTSSON, B.; LINDBERG, J. On the absent ground of transnational partnerships in education: A post-foundational intervention. Globalisation, Societies and Education, v. 17, n. 4, p. 432-444, 2019.

KNUTSSON, B.; LINDBERG, J. Depoliticisation and dissensus in the global partnership for education: rethinking the post-political condition. Journal of International Relations and Development, v. 23, n. 2, p. 436-461, 2020.

LARSON, R. Bit Tyrants: The Political Economy of Silicon Valley. Chicago: Haymarket Books, 2020.

LE GRANGE, L. Curriculum Research in South Africa. In: PINAR, W. F. (Ed.). International Handbook of Curriculum Research. London: Routledge, 2013. p. 466-475.

LEE, R. Métodos não interferentes em pesquisa social. Lisboa: Gradiva, 2003.

MACPHERSON, I. An Analysis of Power in Transnational Advocacy Networks in Education. In: MUNDY, K.; GREEN, A. et al. (Org.). The Handbook of Global Education Policy. Chichester: John Wiley \& Sons, 2016. p. 401-418.

MAZZUCATO, M. The Value of Everything: Making and Taking in the Global Economy. London: Penguin, 2019.

MENASHY, F. Understanding the roles of non-state actors in global governance: evidence from the Global Partnership for Education. Journal of Education Policy, v. 31, n. 1, p. 98118, 2016.

MENASHY, F. The Limits of Multistakeholder Governance: The Case of the Global Partnership for Education and Private Schooling. Comparative Education Review, v. 61, n. 2, p. 240268, 2017.

MENASHY, F. Multi-stakeholder aid to education: power in the context of partnership. Globalisation, Societies and Education, v. 16, n. 1, p. 13-26, 2018.

MENASHY, F. International Aid to Education: Power Dynamics in an Era of Partnership. New York: Teachers College Press, 2019.

MENASHY, F.; DRYDEN-PETERSON, S. The Global Partnership for Education's evolving support to fragile and conflict-affected states. International Journal of Educational Development, n. 44, p. 82-94, 2015. 
A Parceria Global pela Educação e o Financiamento da Educação

MENASHY, F.; SHIELDS, R. Unequal partners? Networks, centrality, and aid to international education. Comparative Education, v. 53, n. 4, p. 495-517, 2017.

MUNDY, K.; GREEN, A.; LINGARD, R.; VERGER, A. The Handbook of Global Education Policy. West Sussex: Wiley-Blackwell, 2016.

OCDE. Net ODA (indicator). 2020. Disponível em: https://data.oecd.org/oda/netoda.htm\#indicator-chart. Acesso em: 13 jan. 2021.

PARREIRA DO AMARAL, M.; STEINER-KHAMSI, G.; THOMPSON, C. Researching the Global Education Industry. Commodification, the Market and Business Involvement. Cham: Palgrave Macmillan, 2019.

RIZVI, F.; LINGARD, B. Globalizing education policy. London: Routledge, 2010.

ROBERTSON, S. L. Researching Global Education Policy: Angles In/Oun/Out... In: VERGER, A.; NOVELLI, M. et al. (Org.). Global education policy and international development: New agendas, issues and policies. London: Bloomsbury Academic, 2012. p. 33-51.

ROBERTSON, S. L.; MUNDY, K.; VERGER, A.; MENASHY, F. Public Private Partnerships in Education: New Actors and Modes of Governance in a Globalizing World. Cheltenham: Edward Elgar Publishing, 2012.

SACK, R. Leadership and the "broken" International Architecture for Education: Where Is the Problem? NORRAG, Highlights, 2020. Disponível em: https://www.norrag.org/leadership-andthe-broken-international-architecture-for-education-where-isthe-problem-by-richard-sack/ Acesso em: 10 jan. 2021.

SILVA, R. D.; OLIVEIRA, J. Privatização da Educação em 24 Países Africanos: tendências, pontos comuns e atípicos. Educação \& Sociedade, Campinas, n. 41, 2020.

SILVA, R. D.; SANTOS, J. G. D.; PACHECO, J. A. Crossed looks: globalisations and curriculum in Guinea-Bissau. Compare: A Journal of Comparative and International Education, v. 45, n. 6, p. 978-999, 2015.

VERGER, A. A política educacional global: conceitos e marcos teóricos chave. Praxis Educativa, v. 14, n. 1, p. 9-33, 2019.

VERGER, A.; NOVELLI, M.; ALTINYELKEN, H. K. Global education policy and international development: an introductory framework. In: VERGER, A.; NOVELLI, M. et al. (Org.). Global education policy and international development: New agendas, issues and policies. London: Bloomsbury Academic, 2012. p. 3-31.

VERGER, A.; NOVELLI, M.; ALTINYELKEN, H. K. Global education policy and international development: New agendas, issues and policies. London: Bloomsbury Academic, 2018.

VERGER, A.; STEINER-KHAMSI, G.; LUBIENSKI, C. The emerging global education industry: analysing market-making in education through market sociology. Globalisation, Societies and Education, v. 15, n. 3, p. 325-340, 2017. 
A Parceria Global pela Educação e o Financiamento da Educação

Rui da Silva é investigador integrado e Presidente da direção do Centro de Estudos Africanos da Universidade do Porto (CEAUP). Mestre e doutor em Ciências da Educação com especialidade em Desenvolvimento Curricular pela Universidade do Minho. Desenvolveu trabalho como investigador, consultor e especialista de educação em Angola, Cabo Verde, Guiné-Bissau, Sudão do Sul e Timor-Leste.

ORCID: https://orcid.org/0000-0003-3369-1285

E-mail: rdasilva.email@gmail.com

Joana Oliveira é professora adjunta da Escola Superior de Educação do Instituto Politécnico de Viana do Castelo e pesquisadora do Centro de Estudos Africanos da Universidade do Porto (CEAUP). Doutora em Ciências pela Universidade do Minho. Pós-doutora em Educação, especializada em Educação Ambiental e para a Sustentabilidade.

ORCID: https://orcid.org/0000-0003-0430-4143

E-mail: joanaoliveira@ese.ipvc.pt 